Jurnal Ilmiah Mahasiswa Kendali dan Listrik
Vol. xx, No. xx, Mounth 2020, page-page. $\mathbf{x x} \sim \mathbf{x x}$
E-ISSN: $2723-598 \mathrm{X}$

\title{
DESAIN ESKALATOR OTOMATIS BERDASARKAN PENGGUNA MENGGUNAKAN PLC OMRON
}

\author{
Agong Chaniago ${ }^{1}$, Sigit Doni ${ }^{2}$, Farli Rossi ${ }^{3}$ \\ Program Studi Teknik Elektro, Fakultas Teknik dan Ilmu Komputer, Universitas Teknokrat Indonesia ${ }^{\mathbf{1 2 , 3}}$ \\ agong@gmail.com, sigit@gmail.com, farli@teknokrat.ac.id
}

\begin{abstract}
Received: (date month year)
Accepted: (date month year)

The escalators that are often encountered in shopping centers are always on even though there are no users. Based on these observations, an escalator is designed to work automatically based on the user. The use of PLC to control the escalator automatically is a design designed to work or be active when there are users and deactivate when there are no users. Based on the test results, it can be concluded as follows: The system has not worked before the work area is activated. The system is active after the work area is activated. The escalator moves up. The timer will run with a maximum time of 10 seconds. If the lower sensor does not have a value of 1 (there are users who are leawt) then the sensor will run for 10 seconds and after that the escalator will stop. If before the 10 second time ends and the lower sensor has a value of 1, the timer value will return to its original value so that the escalator will not turn off. This process will be repeated until the work area is deactivated.
\end{abstract}

Published : (date month year )

Keywords: PLC, Eskalator, Up, Timer, work area

\begin{abstract}
Abstrak
Eskalator yang sering di temui di pusat perbelanjaan selalu dalam keadaan aktof walau tidak ada pengguna. Berdasarkan hasil observasi tersebut maka di rancang sebuah Eskalator yang dapat bekerja secara otomatis berdasarkan pengguna. Penggunaan PLC dalam mengontrol Eskalator secara otomatis merupakan desain yang di rancang untuk dapat bekerja atau aktif saat ada pengguna dan non aktif saat tidak ada pengguna. Berdasarakan hasil pengujian, maka dapat di simpulkan sebagai berikut Sistem belum bekerja sebelum work area di aktifkan. Sistem aktif setelah work area di aktifkan. Eskalator bergerak ke atas.Timer akan berjalan dengan waktu maksimal 10 detik. Jika sensor bawah tidak berniali 1 (ada pengguna yang leawt) maka sensor akan berjalanselama 10 detik dan setelah itu escalator akan berhenti. Apabila sebelum waktu 10 detik berakhir dan sensor bawah berniali 1, maka nilai timer akan kembali kesemula sehingga escalator tidak akan mati. Proses ini akan berulang sampai work area di non aktifkan.
\end{abstract}

Kata Kunci: PLC, Eskalator, Naik, Timer, work area

To cite this article:

Authors. (Year). Title of the article. Jurnal Ilmiah Mahasiswa Kendali dan Listrik, Vol(1), Page-Page.

\section{PENDAHULUAN}

Kata Programmable Logic Controller atau yang sering disingkat dengan PLC seringkali di temui di beberapa tahun terakhir. Pada mulanya alat ini digunakan untuk menggantikan sistem kontrol berbasis relay yang tidak fleksibel dan mahal [1]. Prinsip kerja PLC hampir sama dengan Mikrokontroller dimana keduanya bisa di gunakan untuk mengontrol input dan output [2][3] yang dapat dimasukan program. Arduino merupakan rangkaian elektronik yang bersifat open source, serta memiliki perangkat keras dan lunak yang mudah untuk digunakan. Arduino dapat mengenali lingkungan sekitarnya melalui berbagai jenis sensor dan dapat mengendalikan lampu, motor, dan berbagai jenis aktuator lainnya. Arduino mempunyai banyak jenis, di antaranya Arduino Uno, Arduino Mega 2560, Arduino Fio, dan lainnya [4]. Selama ini sistem kendali di dalam dunia industri sering menggunakan sistem kendali PLC [5].

Eskalator yang sering di temui di pusat perbelanjaan selalu dalam keadaan aktof walau tidak ada pengguna. Berdasarkan hasil observasi tersebut maka di rancang sebuah Eskalator yang dapat bekerja secara otomatis berdasarkan pengguna. Penggunaan PLC dalam mengontrol Eskalator secara otomatis merupakan 
desain yang di rancang untuk dapat bekerja atau aktif saat ada pengguna dan non aktif saat tidak ada pengguna. Programmable Logic Control (PLC) merupakan jantung sistem pengendali atau kontrol yang sering digunakan untuk pengontrolan mesin-mesin produksi yang ada pada dunia industry istem kerja PLC yaitu dengan menguji sinyal input, kemudian memproses sinyal input dan menghasilkan sinyal output sesuai dengan program yang telah disimpan ke dalam memori [6].

\section{TELAAH PUSTAKA}

Beberapa penelitian terkait projek yang menggunakan PLC diantaranya Pengisian Air Minum Otomatis menggunakan PLC. Dalam proses pengisian air minum ke dalam botol, alat ini menggunakan Time Base sebagai batas ukurnya. Dengan demikian hasil pengujian dari alat ini cukup baik, karena dari data yang diperoleh terdapat 12 botol dari 18 botol yang diujikan yang berhasil terisi penuh "PAS". Sehingga penggunaan PLC pada alat ini cukup handal [7]. Penelitian berikutnya berupa pembuatan prototipe lift barang. Prototipe sistem aplikasi lift barang empat lantai yang dirancang untuk mengirim dan memanggil muatan barang telah berhasil dibuat dengan menggunakan pemrograman PLC [8]. Selanjtnya penggunaan PLC dalam merancang dan membuat mesin conveyor penghitung barang menggunakan sistem kendali PLC Omron tipe CPM1A 20 CDR [9]. Penelitian berikutnya berkaitan dengan Eskalator berupa pembuatan escalator lantai satu ke lantai 2. Dalam pembuatanya di awali dengan perencanaan. Perencanaan yang dilakukan meliputi perhitungan panjang eskalator yang akan dipasang, kapasitas daya motor yang akan digunakan dan sistem kontrol eskalator tersebut. Sistem ini dapat melakukan kontrol keamanan dan efisiensi penggunaan listrik pada eskalator. Eskalator akan bekerja apabila ada penumpang yang dideteksi oleh sensor infrared. Jika tidak ada penumpang yang dideteksi maka eskalator akan berhenti bekerja dalam jangka waktu yang telah ditentukan. Ketika terjadi masalah pada sistem yang dapat mengakibatkan kecelakaan terhadap penumpang maka sensor keamanan akan bekerja untuk menghentikan Eskalator [10].

\section{METODE PENELITIAN}

Dalam penelitian ini di awali dengan pengumpulan data terkait dengan penggunaan Eskalator. Biasanya Eskalator yang du jumpai di Pusat perbelanjaan selalu dalam ke adaan menyala walaupun tidak ada penggunanya. Untuk merancang desain escalator otomatis ini dibutuhkan beberapa perangkat yaitu:

\section{PLC}

PLC adalah sebuah alat yang digunakan untuk menggantikan rangkaian sederetan relay yang dijumpai pada sistem kontrol proses Konvensional. PLC bekerja dengan cara mengamati masukan (melalui sensor-sensor terkait) [11].

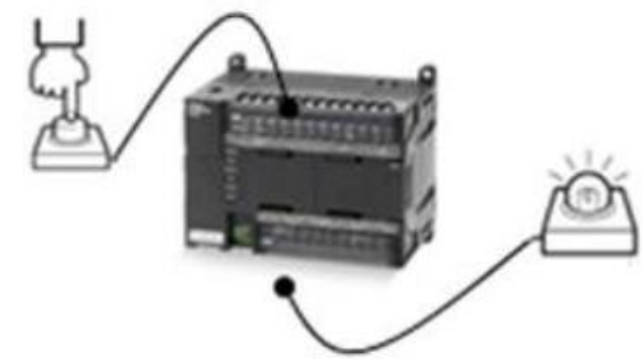

2. Sensor Infrared

$$
\text { Gambar } 1 \text { Programmable Logic Unit (PLC) }
$$

Sensor Infrared adalah komponen elektronika yang dapat mendeteksi benda ketika cahaya infra merah terhalangi oleh benda.Sensor infared terdiri dari led infrared sebagai pemancar dan fototransistor sebagai penerima cahaya infra merah [12].

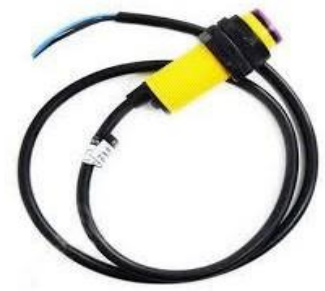

Ganbar 2 Sensor Infrared 
3. Motor DC

Motor DC adalah motor listrik yang memerlukan suplai tegangan arus searah(DC)pada kumparan medan untuk diubah menjadi energi gerak mekanik. Kumparan medan pada motor dc disebut stator (bagian yang tidak berputar) dan kumparan jangkar disebut rotor (bagian yang berputar) [13], [14].

4. Karet Pemutar Anak Tangga

\section{Desain Perancangan Eskalator Naik}

Rancangan Eskalator yang di buat merupakan satu lanati yang mengarah ke atas. Prinsip kerja dari escalator ini adalah berhenti saat tidak ada pengguna, dan akan menyala saat ada pengguna menggunakan sensor Infrared sebagai masukan ke PLC. Berikut desaian Eskalator Naik di sajikan pada Gambar 3.

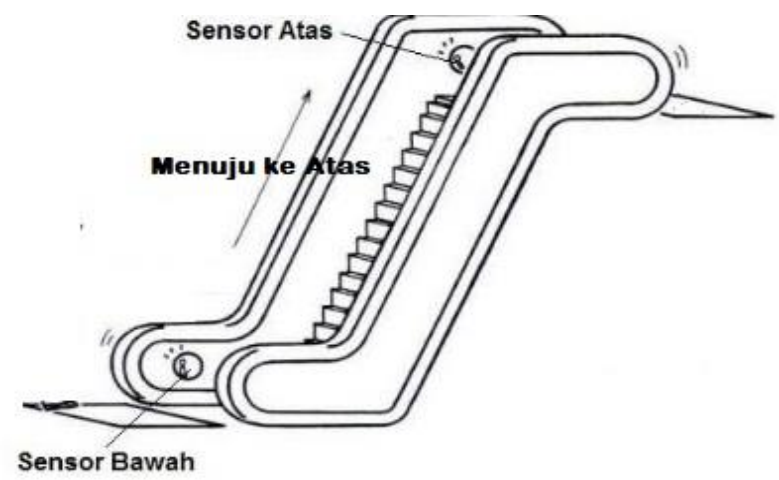

Gambar 3 Desain Eskalator

1. Kondisi awal, eskalator dalam kondisi OFF

2. ketika sensor bawah kondisi High, Motor eskalator aktif dan tangga eskalator bergerak ke atas

3. ketika sensor atas high, maka Timer diaktifkan (nilai maksimal $10 \mathrm{dtk}$ ), jika sensor bawah ada yang lewat (high), timer akan mereset ke angka 0 sehingga eskalator akan tetap aktif.

4. jika selama 10 detik tidak ada yang mengaktifkan sensor bawah (tidak ada yang naik) maka eskalator akan berhenti.

\section{HASIL DAN PEMBAHASAN}

Pemrograman PLC menggunakan Ladder diagram. Software yang di gunakan adalah CX programmer versi 9.5. berikut hasil pemrograman yang telah di buat di sajikan pada Gambar 4 . 
Jurnal Ilmiah Mahasiswa Kendali dan Listrik (JIMEL), Vol: xx, No: xx, page-page

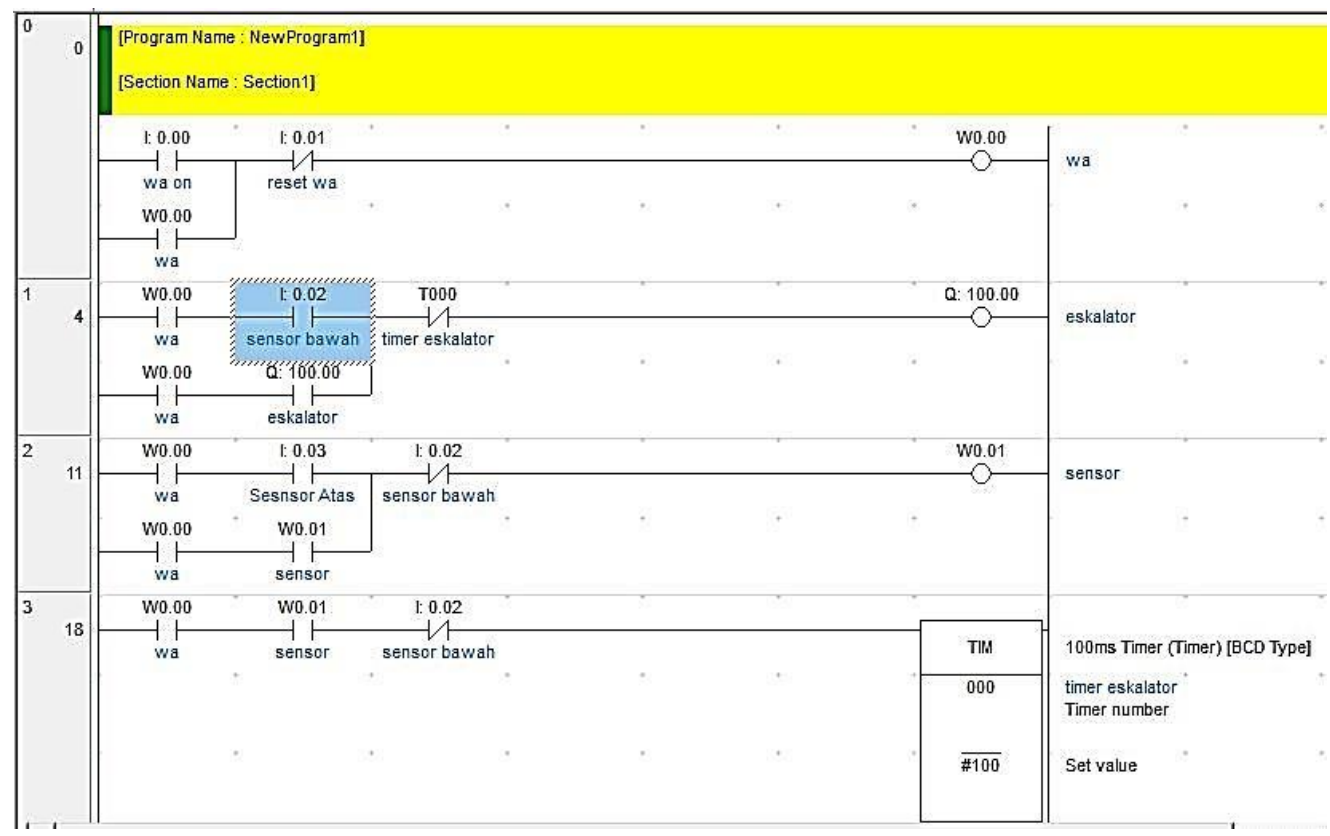

Gambar 4 Ladder Diagram Eskalator naik

Setelah Program telah di buat, selanjutnya adalah pengujian program sesuai dengan perancangan yang telah di buat.

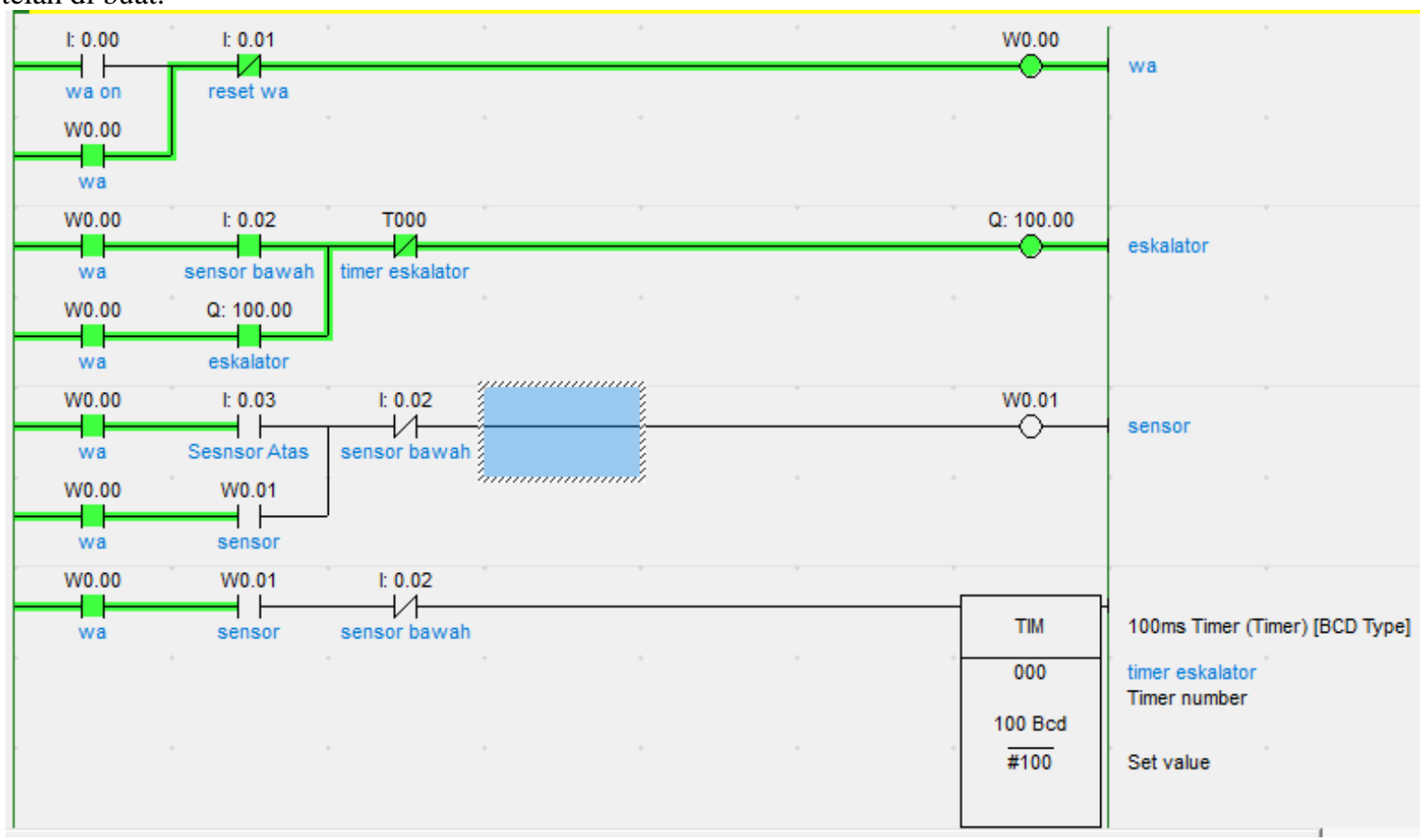

Gambar 5 Sensor Bawah High 


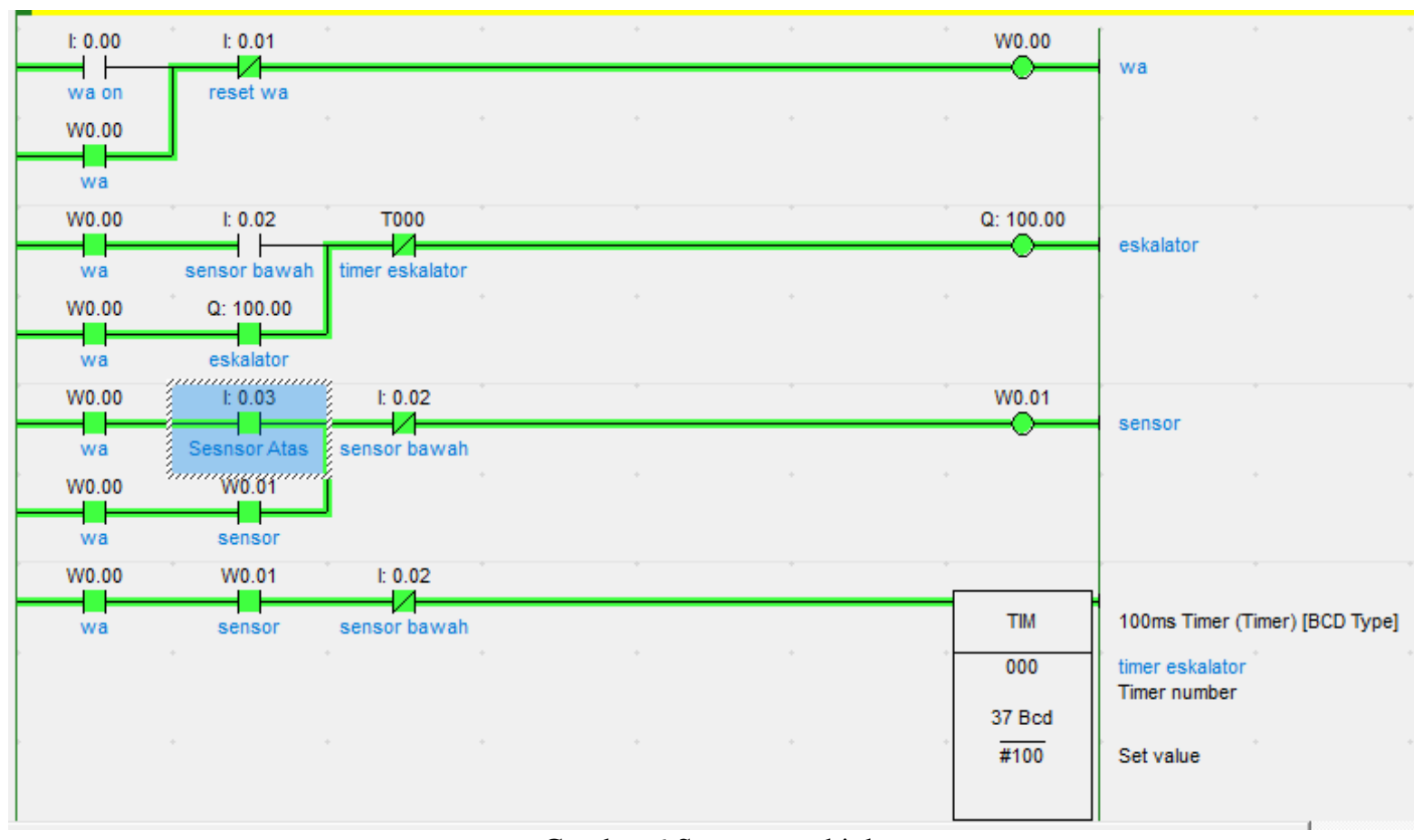

Gambar 6 Sensor atas high

Berikut adalah hasil penggujian Ladder Diagram menggunakan work area yang di sajikan pada Tabel 1.

\begin{tabular}{|c|c|c|c|}
\hline No & Skenario Pengujian & Hasil Pengujian & Kesimpulan \\
\hline 1 & $\begin{array}{l}\text { Memberi nilai } 1 \text { pada sensor } \\
\text { bawah tanpa mengaktifkan } \\
\text { work area }\end{array}$ & Tidak ada yang aktif & $\begin{array}{l}\text { Sistem belum bekerja sebelum } \\
\text { work area di aktifkan }\end{array}$ \\
\hline 2 & Mengaktifkan work area & Sistem aktif & $\begin{array}{l}\text { Sistem aktif setelah work area } \\
\text { di aktifkan }\end{array}$ \\
\hline 3 & $\begin{array}{l}\text { Memberi nilai high (1) pada } \\
\text { sensor bawah }\end{array}$ & Eskalator akan bergerak naik & Eskalator bergerak ke atas \\
\hline 4 & $\begin{array}{l}\text { Memberi nilai } 1 \text { pada sensor } \\
\text { atas }\end{array}$ & Timer akan berjalan (aktif) & $\begin{array}{l}\text { Timer akan berjalan dengan } \\
\text { waktu maksimal } 10 \text { detik. Jika } \\
\text { sensor bawah tidak berniali } 1 \\
\text { (ada pengguna yang leawt) } \\
\text { maka sensor akan } \\
\text { berjalanselama } 10 \text { detik dan } \\
\text { setelah itu escalator akan } \\
\text { berhenti. }\end{array}$ \\
\hline 5 & $\begin{array}{l}\text { Pada saat Timer seang aktif } \\
\text { (belum mencapai waktu } 10 \\
\text { detik) }\end{array}$ & $\begin{array}{l}\text { Sensor bawah mereset timer } \\
\text { ke nilai semula. }\end{array}$ & $\begin{array}{l}\text { Apabila sebelum waktu } 10 \\
\text { detik berakhir dan sensor } \\
\text { bawah berniali } 1 \text {, maka nilai } \\
\text { timer akan kembali kesemula } \\
\text { sehingga escalator tidak akan } \\
\text { mati. Proses ini akan berulang } \\
\text { sampai work area di non } \\
\text { aktifkan. }\end{array}$ \\
\hline
\end{tabular}




\section{SIMPULAN}

Bersarakan asil pengujian Program Eskalator yang di program menggunakan aplikasi CX Programmer, maka dapa di simpulkan:

1. Sistem belum bekerja sebelum work area di aktifkan

2. Sistem aktif setelah work area di aktifkan

3. Eskalator bergerak ke atas

4. Timer akan berjalan dengan waktu maksimal 10 detik. Jika sensor bawah tidak berniali 1 (ada pengguna yang leawt) maka sensor akan berjalanselama 10 detik dan setelah itu escalator akan berhenti.

5. Apabila sebelum waktu 10 detik berakhir dan sensor bawah berniali 1 , maka nilai timer akan kembali kesemula sehingga escalator tidak akan mati. Proses ini akan berulang sampai work area di non aktifkan.

\section{DAFTAR PUSTAKA}

[1] Iebhe, "Apa Itu PLC," ndoware.com, 2020. https://ndoware.com/apa-itu-plc.html (accessed Jan. 06, 2021).

[2] S. Samsugi and A. Burlian, "Sistem Penjadwalan Pompa Air Otomatis Pada Aquaponik Menggunakan Mikrokontroler Arduino Uno R3," pp. 187-197, 2019.

[3] S. Utama, A. Mulyanto, M. Arif Fauzi, and N. Utami Putri, "Implementasi Sensor Light Dependent Resistor (LDR) Dan LM35 Pada Prototipe Atap Otomatis Berbasis Arduino," CIRCUIT J. Ilm. Pendidik. Tek. Elektro, vol. 2, no. 2, pp. 83-89, 2018, doi: 10.22373/crc.v2i2.3706.

[4] S. Samsugi and A. Suwantoro, "Pemanfaatan Peltier dan Heater Sebagai Alat Pengontrol Suhu Air Pada Bak Penetasan Telur Ikan Gurame," pp. 295-299.

[5] B. Wulandari and H. D. Surjono, "Pengaruh problem-based learning terhadap hasil belajar ditinjau dari motivasi belajar PLC di SMK," J. Pendidik. Vokasi, vol. 3, no. 2, pp. 178-191, 2013, doi: 10.21831/jpv.v3i2.1600.

[6] E. M. Indrawati and Nadliroh, "Rancang Bangun Dan Pemrograman Programmable Logic Controller (Plc) Berbasis Mikrokontroler Atmega32," pp. 125-132, 2018.

[7] I. Chaerunnisa, S. B. Mulia, and M. Eriyadi, "Alat Pengisian Air Minum Otomatis ini menggunakan sistem kontrol berbasis Programmable Logic Controller (PLC)," J. Elektra, vol. 3 , no. 2, pp. 61-68, 2018, [Online]. Available: https://pei.ejournal.id/jea/article/download/56/49/.

[8] I. D. Pranowo and D. L. H, "Prototipe Lift Barang 4 Lantai menggunakan Kendali PLC," vol. 8, no. 1, pp. 27-36, 2008.

[9] S. P. Sari, "Rancang Bangun Konveyor Penghitung Barang Dengan Sistem Kendali Berbasis PLC," J. Ilm. Teknol. Rekayasa, vol. 15, no. 100, pp. 168-175, 2014.

[10] M. H. Septiawan, D. Suherman, and P. Murdiyat, "Perencanaan Eskalator Lantai Satu ke Dua pada Gedung Direktorat Politeknik Negeri Samarinda dengan Kendali PLC," J. Tek. Mesin Sinergi, vol. 18, no. 1, p. 80, 2020, doi: 10.31963/sinergi.v18i1.2242.

[11] D. Susandi, A. Rachmat, Y. Samantha, and G. Priyatna, "Perancangan Mesin Pemotongan Bahan Baku Genteng Dengan Sistem Kendali Plc Logic Smart Relay(Sr3B101Fu)," J-Ensitec, vol. 2, no. 01, pp. 41-45, 2015, doi: 10.31949/j-ensitec.v2i01.50.

[12] D. I. Prasetya and M. Mushlihudin, "Sistem Keamanan Sepeda Motor Menggunakan Kata Sandi Berbasis Arduino Nano," J. Ilm. Tek. Elektro Komput. dan Inform., vol. 4, no. 1, p. 11, 2018, doi: 10.26555/jiteki.v4i1.8985.

[13] M. Ruswandi Djalal, D. Ajiatmo, A. Imran, and I. Robandi, "Desain Optimal Kontroler Pid Motor Dc Menggunakan Cuckoo Search Algorithm," NitishKatal.BharatBhushan.AshuAhuja.AnantOonsivilai.UmeshKumarBansal, vol. 7, pp. 121- 
126, 2014.

[14] S. D. R. I Komang, "Rancang Bangun Sistem Pengunci Loker Otomatis Dengan Kendali Akses Menggunakan Rfid Dan Sim 800L," J. Ilm. Mhs. Kendali dan List., vol. 1, no. 1, pp. 33-41, 2020 . 